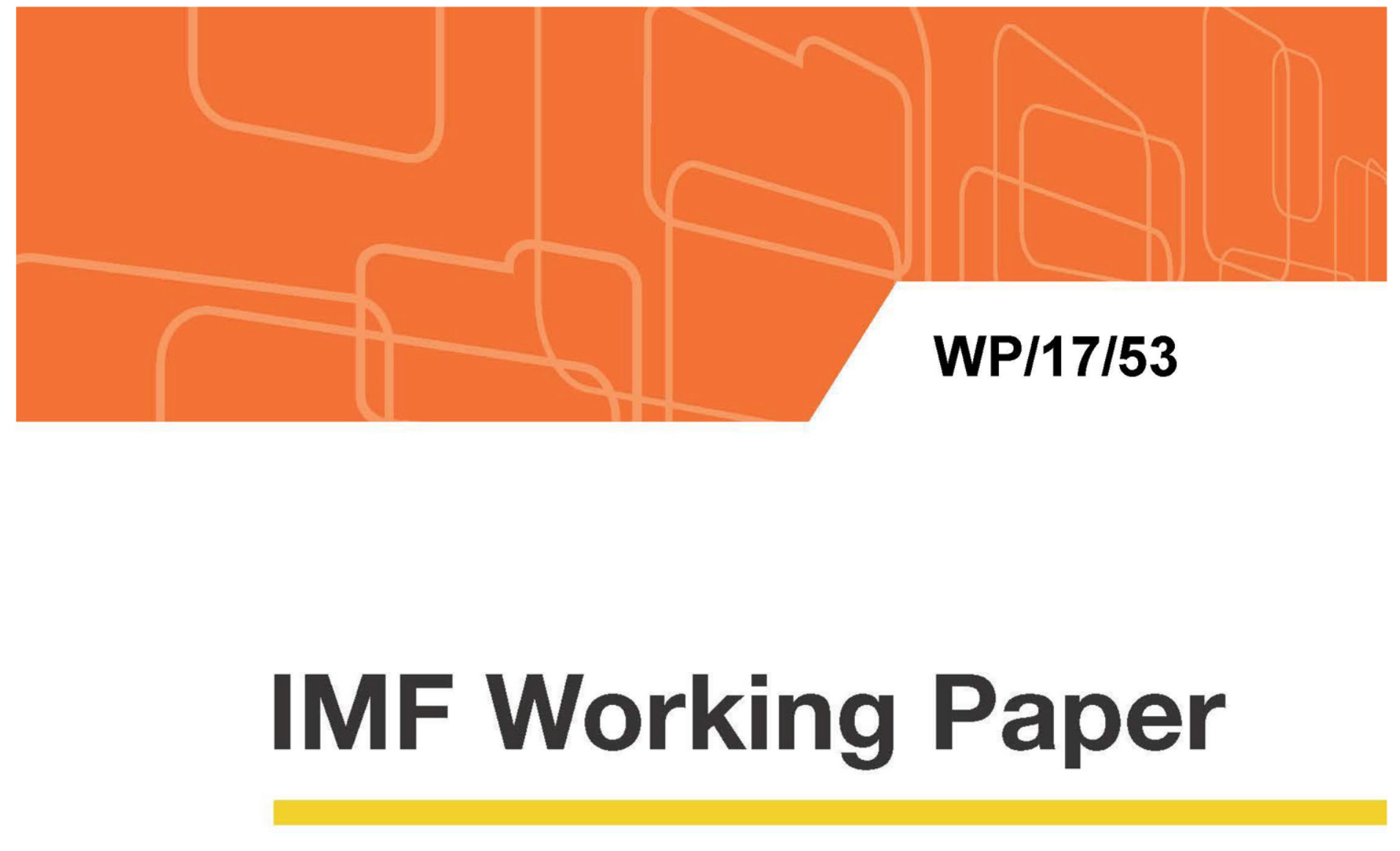

\title{
Pension Reform Options in Chile: Some Tradeoffs
}

by Marika Santoro

IMF Working Papers describe research in progress by the author(s) and are published to elicit comments and to encourage debate. The views expressed in IMF

Working Papers are those of the author(s) and do not necessarily represent the views of the IMF, its Executive Board, or IMF management.

(C) 2017 International Monetary Fund

$\mathrm{WP} / 17 / \mathrm{xx}$

I N T E R N A T I O N A L M O N E T A R Y F U N D 


\section{WP/17/53}

\section{IMF Working Paper}

\section{Pension Reform Options in Chile: Some Tradeoffs}

by Marika Santoro

IMF Working Papers describe research in progress by the author(s) and are published to elicit comments and to encourage debate. The views expressed in IMF Working Papers are those of the author(s) and do not necessarily represent the views of the IMF, its Executive Board, or IMF management.

(C) 2017 International Monetary Fund

$\mathrm{WP} / 17 / \mathrm{xx}$

I N T ER N A T I O N A L M O N E T A R Y F U N D 


\title{
IMF Working Paper
}

Western Hemisphere Department

\section{Pension Reform Options in Chile: Some Tradeoffs}

Prepared by Marika Santoro ${ }^{1}$

Authorized for distribution by Stephan Danninger

March 2017

\begin{abstract}
IMF Working Papers describe research in progress by the author(s) and are published to elicit comments and to encourage debate. The views expressed in IMF Working Papers are those of the author(s) and do not necessarily represent the views of the IMF, its Executive Board, or IMF management.
\end{abstract}

\begin{abstract}
In this paper, we study the macroeconomic impact of pension reform options in Chile, using a dynamic general equilibrium model. The main reform proposal considers raising contributions (employer side) and vehicle additional proceeds to individual accounts and to increase the support of solidarity pensions. We model increased contributions as a labor tax. We find the impact of this reform on GDP to be negative in the near to the medium run, with GDP declining by 0.5 percent by 2021 , as a result of labor tax distortions which lead to a fall in labor supply, investment and to a loss in competitiveness. We also illustrate the main macroeconomics tradeoffs by analyzing alternative reforms, such as using revenues only to improve future pensions or a reform package funded by a mix of higher contributions and indirect taxes.
\end{abstract}

JEL Classification Numbers: D91, E62, H31.

Keywords: Savings, pension reforms, macroeconomic analysis.

Author's E-Mail Address: MSantoro@imf.org

\footnotetext{
${ }^{1}$ The author would like to thank Stephan Danninger, Benjamin Hunt, Dirk Muir, Jorge Roldos, Mauricio Soto and the participants of seminars at the Central Bank of Chile for their comments.
} 


\section{CONTENTS}

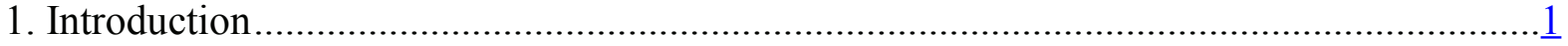

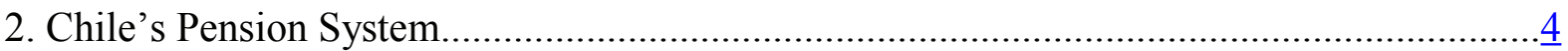

2.1 The Current System ............................................................................................ 4

2.2 Authorities' Reform Proposal .................................................................... $\underline{5}$

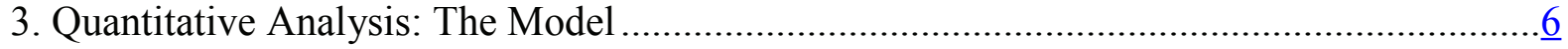

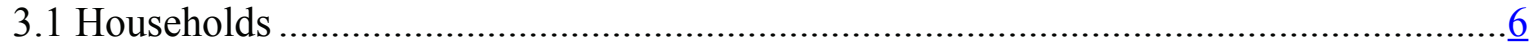

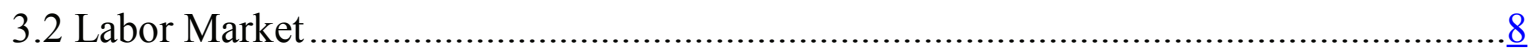

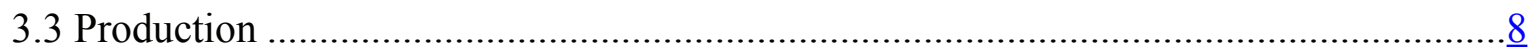

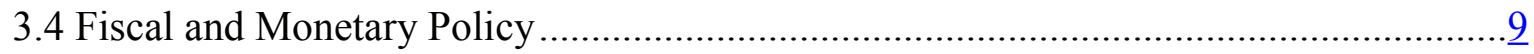

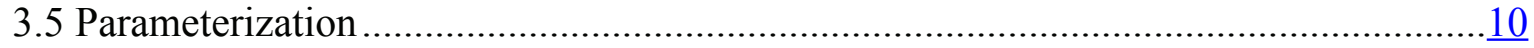

4. Quantitative Analysis: Simulations Results ...............................................................11

4.1 Authorities' Proposed Reform .........................................................................11

4.2 Alternative Reform: Using Indirect Taxes to Finance Solidarity Pensions ..................13

4.3 Alternative Reform: Higher Contributions Only to Individual Accounts ....................14

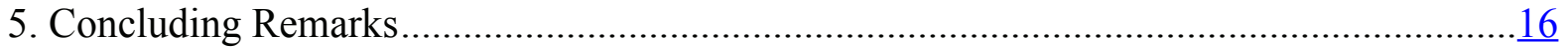

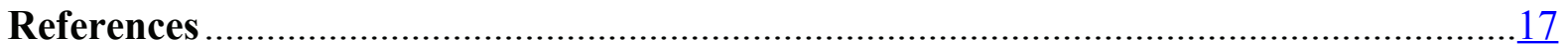




\section{Introduction}

Chile's pension system has come under criticism. Created in 1981, the system currently comprises two pillars. The main pillar is a privately-administrated individual savings pillar providing pension income similar to a defined contribution system. The private pillar was complemented in 2008 by a publicly-funded solidarity pension pillar which provides minimum pensions and top-ups for low private pensions. Private pension savings are large - around 70 percent of GDP - and over the years contributed to a deepening of financial markets. However, the pillar delivers low pensions, especially when compared to levels in other OECD countries. Replacement rates are particularly low for women and for low-skilled workers, often delivering pensions less than minimum wage income.

Low lifetime savings lie at the heart of pension inadequacy. The main reasons are a low contribution rate, frequent employment interruptions, and, in the case of women, a relatively low retirement age of 60 years. In addition, life expectancy is projected to increase by 5 years in the next 30 years making the system unprepared for longer retirement periods.

To address these challenges, the Chilean authorities are considering a set of measures, among the ones suggested by a committee of experts established to study the main issues with the pension system (so-called Bravo Commission). This paper studies the implication of a core proposal, namely to raise mandatory contributions by 5 percentage points over a span of 10 years to 15 percent. ${ }^{1}$ The additional proceeds would be, in yet-to-be-determined shares, allocated to individual accounts and/or to the creation of a new solidarity pillar fund, designed as a pay-as-you-go (PAYG) scheme to raise minimum pensions. Other measures suggested by the Bravo Commission, still being studied by authorities, pertain to changes in compensations of pension funds administrators and increases in the retirement age. The scope of policy changes in these two areas are not clear and as a result their implications have not been analyzed in this paper.

Given the substantial increase in contribution rates in the authorities reform proposal, the economic ramifications could be far reaching. A recent study by the Central Bank of Chile (2017) focuses on the long-run implications of several authorities' proposed options. It shows that targeting additional revenue from higher contributions to individual accounts bears the strongest positive impact on GDP in the long run. In contrast, this paper focuses on the transitional dynamics of the different reform options, showing that their impact and cost in the near term can be important. We study the macroeconomic impact of the proposed policy change over the short to medium term, taking the need to increase contributions as given. ${ }^{2}$ This study does not aim to determine an optimal level of a rate increase, nor the optimal public versus private share of funds allocation.

To carry out this analysis, we use a general equilibrium open economy model (IMF Global Integrated Monetary and Fiscal Model, GIMF). GIMF features agents who behave according to a life-cycle framework (overlapping generations (OLG) agents a la Blanchard, 1985) and

\footnotetext{
${ }^{1}$ President Bachelet announced in August 2016 the main measures of a core proposal that will soon be submitted to Congress.

${ }^{2}$ A committee of experts (so-called Bravo Commission) in Chile issued a report in September 2015. Studies underlying the report have shown that an increase of 5 percentage points in contribution rates to individual accounts is necessary to bring future replacement rates closer to international standards. This paper benefits from some of the descriptive statistics in that report.
} 
liquidity-constrained households, who have no access to financial markets. Since OLG agents are born and die as workers, we will treat the liquidity-constrained as retirees. This is because, similar to retirees, those agents have a high consumption rate and do not optimize over their life-cycle. For instance, they cannot fully re-optimize their life-time consumption plans after any reform announcement (actual retirees have only limited ways to do that).

We model the increase in employer-side contributions as a labor tax since employers de facto will face an increase in labor costs, given wage downward rigidities. While the choice between allocating the increased revenue to individual accounts versus higher current pensions might have different effects on individual welfare, the focus of this paper is on their macroeconomic impact. Distortions have a relatively important impact on domestic variables, competitiveness and exports. In addition, in the near term, the presence of liquidityconstrained (retirees) households with a strong propensity to consume and no possibility to borrow influences demand and prices, amplifying or moderating the initial impact of distortions. We choose to use a multi-country general equilibrium model to capture the role played by the external competitiveness channel. We also exploit a model with liquidityconstrained households since the role of retirees is important in our experiments. Our results are strongly driven by the combination of the openness of the economy and the presence of households with high propensity to consume. We consider these features important for analyzing the macroeconomic impact of a pension reform in a country like Chile.

In the model and for the purpose of this paper, we are not able to distinguish the new solidarity pillar, funded by contributions, from the old solidarity pillar, mainly financed from the general budget. The two components of the solidarity pillar will aim at providing immediate better pensions (transfers), as opposed to the option to devolve the additional revenue to individual accounts, aiming at improving only future pensions. It follows that treating them as a unique pillar has no impact on the near-term macroeconomic results of this analysis, which abstracts from distributional or welfare considerations. For this reason, in the remaining of the paper when we refer to solidarity pensions there will be no distinction between the two components of the solidarity pillar.

Figure 1: Chile: Pension system and reform options
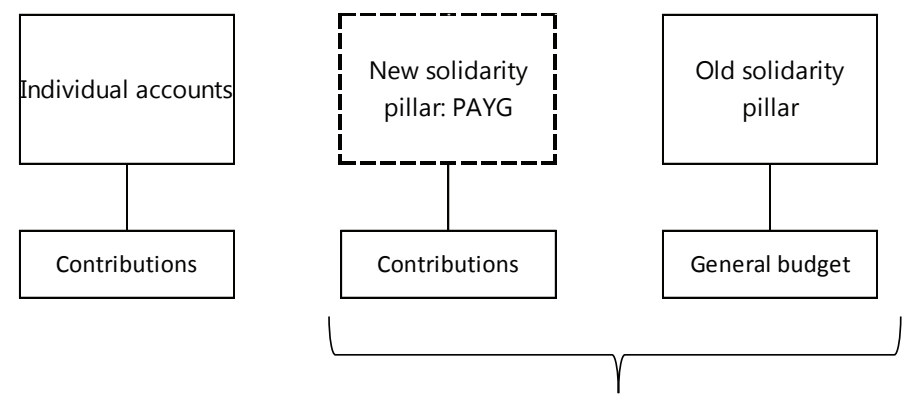

Unique fund in the model

We find that depending on the use of the revenue from higher contributions and the types of financing, reforms can have a different, albeit moderate, macroeconomic impact over the near to medium term. Labor tax distortions increase production costs and inflation, and lead 
to a fall in labor supply, investment and to a loss in competitiveness. We evaluate two cases:

When the extra revenue is used partly to increase current solidarity pensions, higher current transfers (pensions) will generate stronger demand and sustain growth in the near to the medium term. At the same time, though, this channel will generate extra pressure on prices, further worsening the real effective exchange rate position. However, higher aggregate consumption more than compensates for the loss on the external front.

On the contrary, when higher revenues are only used to ensure higher future pensions (i.e. used to increase individual savings accounts), lower consumption and higher savings in the near term generate lower goods demand and inflation, relative to the case when the extra revenue is partly used to finance (current) solidarity pensions. Interest rates also decrease by less. In all, domestic investment is further discouraged, despite lower domestic inflation creates a positive effect on the real effective exchange rate boosting competitiveness.

In model simulations, GDP is 0.5 percent lower than a baseline with no reform by 2021 in the case where contributions are used at equal parts for the private and the solidarity pillar. Since both components of the solidarity pillar embed some form of redistribution from taxpayers, we also analyze the possibility to use alternative taxes (e.g. indirect taxation) to finance better current pensions. Growth costs are lower if revenue for the solidarity pillar is financed through indirect taxes. Finally, output is 0.7 percent lower over the same period in the case when higher revenues are used only to increase individual savings accounts. In other words, boosting future pensions has macroeconomic costs in the near term as less funds are available for supporting low income pensions. On the other hand, improving current pensions supports demand, partly offsetting the effects of higher contribution rates, but leads to less savings for future generations, lower future pensions, and sustained needs to support low-income pensioners. Balancing these trade-offs should be an important guiding principle when deciding about the key parameters of the pension reform.

Sensitivity tests show that labor supply elasticity plays an important role and the negative impact on growth in the near term can become large as labor becomes increasingly elastic. Importantly, as mentioned above, a pension reform package funded by a mix of higher contributions and indirect taxes would carry lower growth costs than one funded exclusively by increased contribution rates.

A framework similar to ours was exploited for simulations of pension reforms in Karam et al. (2010) and results are comparable in magnitude for options that consider increasing contribution rates to finance higher future pensions. More generally, this paper relates to two strands of literature. It relates to the literature on pension reforms in life-cycle models, including Auerbach and Kotlikoff (1987), De Nardi, Imrohoroglu and Sargent (2001), Nishiyama and Smetters (2007) and Nishiyama (2011). However, those papers consider pension reforms in a closed economy. Our paper shows that by using an open-economy framework one can identify additional channels with important impacts on real activity, besides intertemporal allocation.

This paper also relates to the literature dealing with life-cycle aspects in multi-country models. Fehr, Jokisch and Kotlikoff (2005 and 2008) analyze the macroeconomic implications of differential demographics on capital inflows and outflows in a group of advanced countries. However, despite accounting correctly for life-cycle aspects implied by demographic changes, these models abstract from competitiveness issues. We believe those aspects are otherwise important in analyzing reforms in a country like Chile. 
The organization of the paper is as follows. Section 2 describes the main features and issues with the current pension system in Chile. Section 3 delineates the main tracts of the model used for the simulations and its parameterization. In Section 4, we discuss the simulations results and sensitivity. Section 5 concludes.

\section{Chile's pension system}

\subsection{The current system}

Chiles pension system is based mainly on a contributory scheme with individual savings accounts, administrated by privately-owned corporations (Administradoras de Fondos de Pensiones, AFPs). The system was created in 1981 and sought to establish an intergenerationally fair system while reducing the role of the state in social security. Mandatory contributions to the system are set at 10 percent of annual income. For old-age pensions, the minimum retirement age is set at 60 for women and 65 for men. Pensioners with low life time-savings and individuals not covered by the contributory system fall under a publicly-funded solidarity pillar, introduced in 2008, which currently covers 60 percent of the poor at a fiscal cost of 0.7 percent of GDP per year.

The system is, however, not delivering adequate benefits for a large share of retirees. Chiles average pension is below the minimum wage and estimated replacements rates are very low relative to the OECD average of 63 percent, particularly for women (Table 1).

Table 1: Chile: Median replacement rates

\begin{tabular}{cccc}
\hline & Total & Men & Women \\
\hline & & (in percent, average 10 last salaries) & \\
Actual replacement rates (2007-14) & & 48 & 24 \\
Self-financed pension (indiv. accounts) & 34 & 60 & 31 \\
Self-financed pension + public benefits & 45 & & \\
& & 24 & 34 \\
Projected replacement rates (2007-14) & 15 & 41 & 34 \\
Self-financed pension (indiv. accounts) & 37 & & \\
Self-financed pension + public benefits & 37
\end{tabular}

Source: Informe Final, Comision Presidencial Pensiones, Chile 2015.

In 2015, a commission (Comision Asesora Presidencial Sobre el Sistema de Pensiones or so-called Bravo Commission) comprising international and domestic experts identified several shortcoming of the current system. Low contribution rates of 10 percent and short contribution periods - largely reflecting discontinuous career paths - were found to be the main reasons for low replacement rates. Furthermore, the coverage of workers under the system is narrow (e.g., self-employment, informal labor) and administrative costs are high (Tapia and Yermo, 2008). The solidarity pillar does not provide adequate minimum pensions, since levels are only 40 percent of the minimum wage and just above the poverty line (Bravo Commission, 2015). In addition, because of population aging, spending would need to increase 
by an additional 0.2 percent of GDP in the course of the next decade in order to maintain current benefits for an increasing pool of beneficiaries.

Current low replacement rates, associated with the current contributions level, will provide pension incomes even lower if one considers the projected increase in life expectancy in future decades. According to UN estimates, population age 65 and older is projected to more than double by 2050 and life expectancy will increase by 5 years (Figure 2).

Figure 2: Chile: Population projections

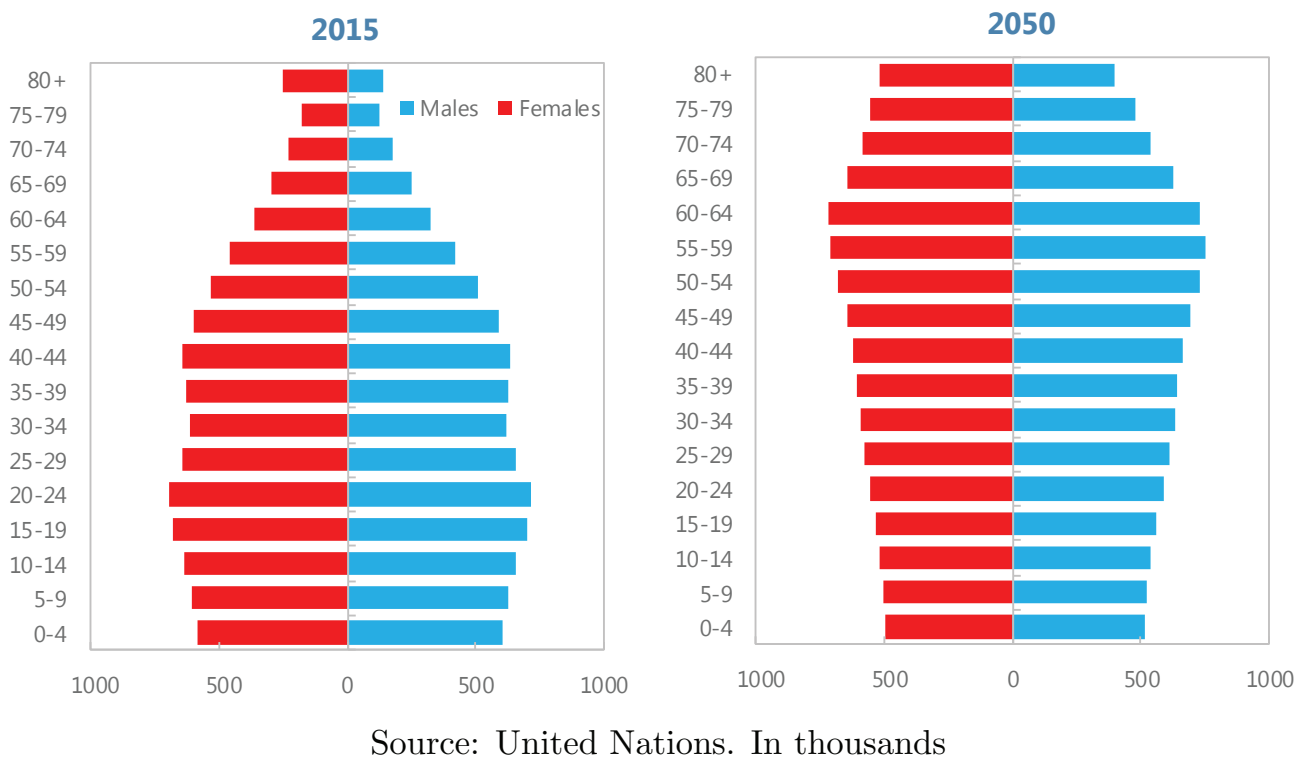

\subsection{Authorities' reform proposal}

Drawing on the recommendations of the Bravo Commission report (2015), Chile's government announced in August plans to: 1) gradually increase contribution rates by 5 percentage points over a 10-year time span; 2) allocate the additional revenue in yet-to-be-determined shares to individual accounts and for solidarity or pay-as-you-go (PAYG) related payments (which improve pensions of current retirees), and 3) reduce costs of the pension fund administration (although, it is still not clearly defined what measures will be adopted). The government is not planning to change the retirement age, at the moment. The increase in contributions by 5 percentage points was estimated to increase replacement rates by up to 20 percentage points in the long-run, bringing them closer to OECD standards.

The choice between allocating the increased revenue from higher contributions to individual accounts versus higher current pensions has non-trivial implications on aggregate consumption and on whether individuals regard the contributions as a pure tax or forced savings. To illustrate these forces, in the next section, we will use a general equilibrium model and conduct an analysis of the authorities proposed reform alongside with some alternative policies. 


\section{Quantitative analysis: the model}

In this section, we describe the IMF's Global Integrated Monetary and Fiscal (GIMF) model used for our simulations. The GIMF model is a multi-country dynamic general equilibrium model with optimizing households and firms, and with a public sector that defines fiscal and monetary policies in each country. The model features a financial accelerator and several layers of production, which make it suitable for addressing a wide range of research questions. ${ }^{3}$ For the purpose of the present paper, it is important to highlight some characteristics of the model. The model features two types of households (life-cycle and liquidity-constrained), firms, fiscal and monetary sectors. The households sector is characterized by decisions that take into account life-cycle profiles but there is only a stylized representation of generations, following Blanchard (1985).

There is no explicit demographics in the model and households age is just a proxy for identifying profiles of labor supply, consumption and asset accumulation. The age distribution in the model, i.e. the measure of households in each age class, does not change over time, therefore is no explicit account of population aging. Since in reality Chile is in the midst of demographic transition, in our baseline, we will consider the pressure that increased elderly would exert on solidarity pension spending as a cut in pensions per capita in the model. Another important feature of the model is that firms belong to the tradable and non-tradable sectors but there is not an explicit the commodity/mining sector. We consider the absence of this feature to be minor for the purpose of the simulations performed in this paper.

In this section, we present the relevant features of the model that better fit the topic of the present analysis. For a more comprehensive description of the theoretical structure of the model, see Kumhof et al. (2010). Readers familiar with the setup of the model can skip to section 3.5 where we discuss the Chile specific calibration.

\subsection{Households}

Each country is populated by two types of households, optimizing agents with a finite time horizon and liquidity-constrained, respectively in measure $(1-\psi)$ and $\psi$. The optimizing agents are OLG households with finite planning horizons as in Blanchard (1985), whose horizon is determined by some degree of myopia $\theta$. In each instance, an index $a$ denotes household's age and an index $t$ denotes a time period and each period corresponds to one year. Each of these agents faces a constant probability of death $(1-\theta)$ in each period, at which point they are replaced by new households so that the proportion of households in the economy remains constant. OLG agents are born and die as workers.

Labor productivity declines at a constant rate over the lifetime of both types of households. Both households pay direct taxes on labor income, indirect taxes on consumption spending, and a lump-sum tax. Additionally, they receive transfers from the government. They optimally choose consumption, assets, and labor supply to maximize the following lifetime

\footnotetext{
${ }^{3}$ Different layers of agents in the production side of the economy are also useful to address the complexity of computational aggregation.
} 
utility function:

$$
E_{t} \sum_{s=0}^{\infty}(\beta \theta)^{s}\left[\frac{1}{1-\gamma}\left(\left(\frac{c_{a+s, t+s}^{O L G}}{\left[C_{t+s-1}\right]^{\nu}}\right)^{\eta}\left(S_{t}-l_{a+s, t+s}^{O L G}\right)^{1-\eta}\right)^{1-\gamma}\right],
$$

where $\gamma>0$ is the coefficient of relative risk aversion, $\eta$ is the preference parameter for consumption, and $\beta$ is the discount factor. In equation (1), $\left(S_{t}-l_{a, t}^{O L G}\right)$ is the available time for leisure of the OLG households of age $a$ in period $t$, where $S_{t}$ is the total available time and $l_{a, t}$ is the time resource devoted to labor supply. In turn, $c_{a, t}^{O L G}$ denotes the consumption of the OLG household of age $a$ in period $t$ and is given by a CES aggregate over final retailed consumption varieties $c_{a, t}^{O L G}(i)$, with elasticity of substitution $\sigma_{R}$ :

$$
c_{a, t}^{O L G}=\left(\int_{0}^{1}\left(c_{a, t}^{O L G}(i)\right)^{\frac{\sigma_{R}-1}{\sigma_{R}}} \mathrm{~d} i\right)^{\frac{\sigma_{R}}{\sigma_{R}-1}}
$$

Preferences in equation (1) allow for external habit persistence on previous aggregate consumption, where the intensity of the persistence is governed by $\nu$. The maximization is constrained by the following household's budget identity:

$$
\begin{array}{r}
P_{t}^{R} c_{a, t}^{O L G}\left(1+\tau_{c, t}\right)+P_{t} \tau_{a, t}^{l s, O L G}+\sum_{j=G, N, T} B_{a, t}^{j}+\epsilon_{t} F_{a, t}=\frac{1}{\theta}\left[i_{t-1} B_{a-1, t-1}^{G}\right. \\
+i_{t-1}\left(1+\eta_{t-1}^{b}\right) B_{t}^{j=N, T}+ \\
\left.i_{t-1} \epsilon_{t} F_{a-1, t-1}\left(1+\xi_{t-1, f}\right)\right]+W_{t} \Phi_{a, t} l_{a, t}^{O L G}\left(1-\tau_{L, t}\right) \\
+\sum_{y=\text { firms,unions }} \int_{0}^{1} D_{a, t}^{y}(i) \mathrm{d} i+P_{t} b m_{a, t}+P_{t} \Upsilon_{a, t}^{O L G}
\end{array}
$$

where $P_{t}$ is the price of consumption goods, used as a numeraire, $P_{t}^{R}$ is the retailer price, $W_{t}$ is the nominal wage, $i_{t}$ is the nominal interest rate, $\tau_{L, t}$ is the tax rate on labor income, $\Upsilon_{a, t}^{O L G}$ are the lump-sum transfers that OLG households of age $a$ receive from the government, $\tau_{a, t}^{l s, O L G}$ is a net lump-sum taxes tax paid to the government by an households of age $a, B_{a, t}^{G}$, $B_{a, t}^{N}$, and $B_{a, t}^{T}$ are age $a$ household's holdings of bonds issued respectively by the government, the banks lending to the non-tradable and tradable sectors, $F_{a, t}$ is age $a$ household's holdings of foreign bonds denominated in foreign currency, and converted at the nominal exchange rate $\epsilon_{t}$. The interest rate paid on domestic bond accounts for the domestic risk-premium $\xi_{t, b}$, with a value of $\xi_{t, b}<0$ indicating that the private sector faces a larger marginal funding rate than the public sector. Likewise, for foreign bond holdings, the interest rate is adjusted to account for a foreign exchange risk-premium, $\xi_{t, f}$.

The liquidity-constrained households decide how much to consume but they do not have access to credit markets. Their decision does not aim to smooth consumption and therefore they are constrained to consume their after-tax income in every period. Their objective function is similar to the utility function of the OLG households, but we can ignore generations in this case, since they all behave identically given that they do not save:

$$
E_{t} \sum_{s=0}^{\infty}(\beta \theta)^{s}\left[\frac{1}{1-\gamma}\left(\left(\frac{c_{t+s}^{L I Q}}{\left[C_{t+s-1}\right]^{\nu}}\right)^{\eta}\left(S_{t}-l_{t+s}^{L I Q}\right)^{1-\eta}\right)^{1-\gamma}\right]
$$


where $c_{t}^{L I Q}$ features preferences for variety as in equation (2). Optimization is subject to the following budget constraint, which outlines their dependence on current income:

$$
P_{t}^{R} c_{t}^{L I Q}\left(1+\tau_{c, t}\right)+P_{t} \tau_{t}^{l s, L I Q}=W_{t} \Phi_{t} l_{t}^{L I Q}\left(1-\tau_{L, t}\right)+P_{t} \Upsilon_{t}^{L I Q}
$$

In this version of the model, they do not decide how much to work. ${ }^{4}$ For the purpose of this paper, we will treat liquidity-constrained households as retirees. Similar to retirees, those agents have a high consumption rate and do not (have limited opportunities to) optimize over their life-cycle. For instance, they cannot fully re-optimize their life-time consumption plans after any reform announcement (actual retirees have only limited ways to do that). Labor income for the liquidity-constrained households can be considered as a pension transfer, with some caveats. Developments in the labor markets affect their income and budget constraint. That channel can be seen as a change in resources available for pension transfers when labor markets are weaker or stronger.

\subsection{Labor market}

The labor market is subject to imperfect competition. In particular, the model features a continuum of unions that are perfectly competitive in their input market and monopolistically competitive in their output market, where they offer different varieties of labor inputs to firms.

Given the imperfect substitutability between the labor supplied by different unions, unions are able to set a wage markup, which represents a wedge between the marginal product of labor and the marginal rate of substitution between consumption and leisure. Additionally, unions are subject to real rigidities in their wage setting, captured by quadratic adjustment costs.

\subsection{Production}

In the model, the production process takes place in several layers. In each layer of production, agents face competitive input markets and monopolistically competitive output markets. First, there is a continuum of manufacturing firms that produce tradable and non-tradable goods, using capital from capital goods producers and labor from unions, in a CES fashion.

Manufacturing firms are subject to nominal rigidities in price setting, and real rigidities in their labor hiring. The production of capital stock is subject to quadratic adjustment costs, which depend positively on the deviation of investment at time $t$ from of investment at $t-1$. The presence of adjustment costs causes the shadow value of capital or marginal $q$ to deviate from a simple price in terms of consumption goods. Thus, the marginal $q$ is a function of the adjustment costs, the capacity utilization, the interest rate, the marginal product of capital $(\mathrm{MPK})$ and the tax rate on capital income.

Manufacturing firms sell intermediate tradable and non-tradable goods to domestic distributors, and intermediate tradable goods to import agents in foreign countries. There are three layers of distributors until the last one that produces final consumption and investment goods, respectively, combining domestic and foreign final output. Their price setting is subject

\footnotetext{
${ }^{4}$ Labor supply in equilibrium is set proportional to the OLG households.
} 
to nominal rigidities and changes in the volume of their imports are subject to quadratic adjustment costs.

The final consumption good is sold to retailers and to the government. The final investment good is sold to capital goods producers and to the government. Retailers sell their output to households in a monopolistic competitive market and they are subject to real price rigidities. Finally, capital goods producers produce the capital input used by manufacturing firms and are subject to investment adjustment cost. The financial accelerator mechanism, in the spirit of Bernanke, Gertler and Gilchrist (1999), enters at this layer of the model.

\subsection{Fiscal and monetary policy}

The primary purpose of the fiscal policy is to ensure a a stable government debt-to-GDP ratio in the long run, thus excluding the possibility of sovereign default. At the same time, Chile fiscal rule allows for some flexibility to respond to the business cycle, by performing countercyclical fiscal policy: ${ }^{5}$

$$
\left(\frac{\Sigma}{Y}\right)_{t}=\left(\frac{\Sigma}{Y}\right)^{S S}+d^{B}\left[\left(\frac{B}{Y}\right)_{t}-\left(\frac{B}{Y}\right)^{S S}\right]+d^{Y}\left(\frac{Y_{t}}{Y^{S S}}\right),
$$

where $\left(\frac{\Sigma}{Y}\right)_{t}$ is the budget surplus as a share of GDP, $\left(\frac{\Sigma}{Y}\right)^{S S}$ is the equivalent long-run ratio, $\frac{B}{Y}$ is the debt-to-GDP ratio and $\frac{Y_{t}}{Y^{S S}}$ is the output gap. The parameters $d^{B}$ and $d^{Y}$ govern the strength of the stabilization channels, through a reaction to deviations of debt and to the output gap.

Fiscal policy is conducted using a variety of fiscal instruments related to taxation and spending, and through the issuance of government debt. The sources of tax revenues are labor income tax, consumption taxes, taxes on the return to capital, and lump-sum taxes. Government spending takes the form of consumption and investment expenditures, and lump-sum transfers to all households.

Regarding monetary policy, we consider a central bank that follows a strict inflation targeting regime, in order to capture the case of Chile. In this case, the monetary authority varies the policy rate in order to achieve a stable target rate of inflation over time, using a Taylor rule of the following type:

$$
i_{t}=\left(i_{t-1}\right)^{\delta_{i}} E_{t}\left[\left(\frac{\pi_{t}^{\delta_{p}} \pi_{t+1}^{1-\delta_{p}}}{\pi^{*}}\right)^{\left(1-\delta_{i}\right) \delta_{\pi}}\left(\frac{Y_{t}}{Y^{S S}}\right)^{\left(1-\delta_{i}\right) \delta_{Y}}\left(\frac{\eta_{t}}{\eta^{*}}\right)^{\delta_{\eta}}\right],
$$

where $i_{t}$ is the policy rate, which depends on: (i) previous period rate $i_{t-1}$ with intensity $\delta_{i}$; (ii) a weighted average of present and forward inflation $\pi$ (with weight $\delta_{p}$ ) and its deviation from target inflation level $\pi^{*}$, with intensity $\delta_{\pi}$; (iii) the deviation of GDP from its steady-state (non-inflationary) level; (iv) the depreciation of the nominal exchange rate $\eta$ from some reference level $\eta^{*}$ with intensity $\delta_{\eta}$.

\footnotetext{
${ }^{5}$ see IMF (2015)
} 


\subsection{Parameterization}

In this section, we describe the baseline model specification and calibration assumed for the quantitative exercise. Throughout the paper, we simulate policy experiments using a three-country version of the GIMF model. The domestic economy is Chile, whose GDP accounts for a very small fraction of the world GDP (0.6 percent), the other two countries are the Emerging Asia (EA) and the Rest of the World (RW), which represent respectively 17.4 percent and 82.0 percent of world GDP.

Table 2 displays the key parameters for the three countries. Most of the parameters are calibrated according to Kumhof et al. (2010) for the case of the US, except for some parameters that are key to pin down the specific behavior of the Chilean economy, reported in Table 2. Given the strong reliance of Chile on imports of final goods, the domestic economy is

Table 2: Parameter values for the baseline calibration

\begin{tabular}{lccc}
\hline \hline & Chile & Emerging Asia & Rest of the World \\
\hline Real adjustment costs of imports & 1.5 & 1.0 & 1.0 \\
Capital share in production $(\alpha$, in $\%)$ & & & \\
$\quad$ Tradable sector & 52.0 & 47.2 & 45.0 \\
$\quad$ Non-tradable sector & 38.0 & 38.5 & 30.0 \\
Discount factor $(\beta)$ & 0.966 & 0.968 & 0.967 \\
Share of liquidity-constrained households $(\psi)$ & 0.3 & 0.4 & 0.4 \\
Frisch elasticity of labor supply & 0.5 & 0.5 & 0.5 \\
Coeff. on output gap $d^{Y}$ (fiscal rule) & 0.25 & 0.25 & 0.4 \\
Coeff. on $t-1$ interest rate $\delta_{i}$ (monetary rule) & 0.3 & 1.0 & 0.3 \\
Coeff. on deviation from inflation target $\delta_{\pi}($ monetary rule) & 1.5 & 0.0 & 1.2 \\
Weight on current inflation $\delta_{p}$ (monetary rule) & 0.25 & 0.0 & 0.25 \\
\hline
\end{tabular}

characterized by higher levels of real adjustment costs to imported final goods (1.5 for Chile versus 1 for the other two regions, following Kumhof et al., 2010). This captures the fact that in small open economies agents cannot quickly substitute imported goods with domestic goods, as the economy's production scale and variety is limited and this gives rise to high adjustment costs. Consistently, the share of tradable goods on real income is 50 percent, higher in Chile than in the RW (40 percent).

For simplicity and tractability, the production function is specified as a Cobb-Douglas:

$$
F\left(A, T ; K_{t}, L_{t}\right)=A_{t}\left(K_{t}^{\alpha}+\left(T_{t} L_{t}\right)^{(1-\alpha)}\right),
$$

I set the capital factor share parameters $\alpha$ to 0.52 percent, in the tradable sector, and of 0.38 percent in the non-tradable sector, higher than in the RW ( 0.45 for the tradable and 0.30 for the non-tradable sectors) to capture both the high intensity of capital in the mining sector and high inequality in the distribution of assets and income in Chile. ${ }^{6}$

I calibrate the time preference parameter $\beta$ to be consistent with a capital-to-GDP ratio of 179 (this implies $\beta=0.966$ ). The share of liquidity constrained agents in the economy $(\psi)$ is parametrized to 0.33 to match the share of retirees to workers in Chile.

\footnotetext{
${ }^{6}$ At 0.52 , the income Gini coefficient for Chile points at an inequality at least 20 percent higher than in advanced countries.
} 
Regarding fiscal policy, the particular design of the fiscal rule allowed Chile in the past to use some degree of countercyclical policy behavior. Chile's fiscal policy does not target a specific debt-to-GDP ratio. The coefficient that regulates the reaction of fiscal surpluses to the output gap $d^{Y}$ is set at 0.25 as in Kumhof et al. (2010) for EA, while the coefficient that regulates the reaction of fiscal policies to the debt-to-GDP ratio is instead set to 0 .

The objective of the monetary authority in Chile is to target a given long-run level of inflation, with a single mandate. The coefficients on $t-1$ interest rate, and on the deviation from inflation target for the Taylor-type reaction function are set similar to the case of the euro area as in Kumhof et al. (2010) at 0.3 and 1.5, respectively. The coefficients that govern the response for the policy rate to the output gap and to the exchange rate are set to zero given that the Chile's central bank follows a single mandate.

\section{Quantitative analysis: simulations results}

The goal of this section is to conduct a positive analysis of the impact of the main reform announced by authorities on the macroeconomy over the near to the medium run, taking as given the need to increase contributions. In addition to the basic reform proposal, we will analyze alternative scenarios. These are motivated by the uncertainty of the use of additional revenue from increased contributions. For this reason, we will analyze an alternative case where the revenue is only channeled to individual accounts.

Furthermore, individual accounts and the solidarity pillar are different in nature. The different nature of the two systems would open options for funding the solidarity pillar with alternative taxes, therefore we also consider a case in which additional revenue is raised through a combination of higher contribution rates and indirect taxation.

\subsection{Authorities' proposed reform}

In this section, we will analyze the impact of the reform relative to a baseline. The baseline projection envisages an increase in old-age workers, as a result of population aging and a pressure towards an increase in fiscal funding for the solidarity pension. Since the model features no explicit aging of the population, under a baseline with no-policy action, we assume that an increasing share of lower-income class elderlies will not be covered by the solidarity pensions (i.e. receive a cut in lump-sum transfers).

The authorities' proposed reform simulations are as follows:

1. The increase in (employer-side) contributions is modeled as a gradual increase in labor tax by 5 percentage points, over 10 years.

2. A fraction of the additional resources from higher contributions (assume 50 percent) will be rebated back to the retirees (liquidity-constrained) through solidarity pensions (transfers).

3. The remaining fraction (the other 50 percent) will be allocated to a public asset/fund (i.e. reduction of net debt for the government) and be used for rising transfers in the future (mimicking better future contributory pensions), starting gradually after 10 years. 
Figure 3 displays the impact of the reform on the main macroeconomic variables. The charts plot the percentage differences of all variables from baseline.

Figure 3: Impact of the proposed reform on main macroeconomic variables
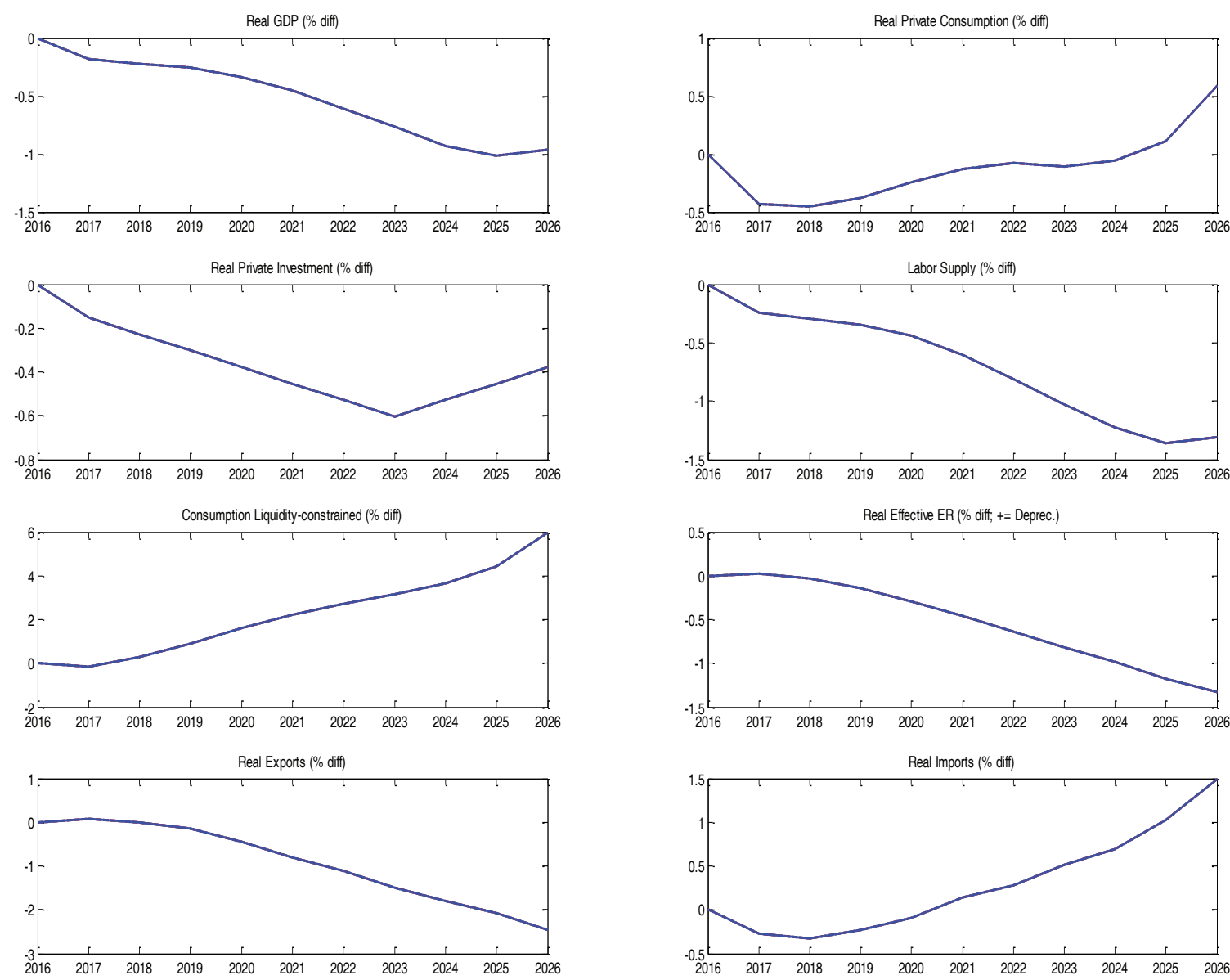

Source: IMF calculation. In percentage deviation from steady state.

Real GDP declines by about 0.5 percent by 2021 (0.1 percentage points less growth per year in the first 5-6 years), relative to a no-policy-action baseline, because the pension reform implies higher taxes on labor, lower employment, lower aggregate consumption (due to a fall of OLG/highly contributing agents consumption) and investment. However, liquidityconstrained agents are better-off than in the baseline as higher targeted transfers (pensions) raise their consumption.

Exports are also lower in the reform scenario as higher labor cost dampens competitiveness, leading to an appreciation of the real effective exchange rate (REER). The presence of liquidityconstrained (retirees) households with a strong propensity to consume and no possibility to borrow influences demand and prices, amplifying the initial impact of distortions on competitiveness. Given the importance of labor supply response to increase in labor tax, we perform a sensitivity analysis by varying the degree of labor supply elasticity (Frisch elasticity). ${ }^{7}$ The strongest negative impact on output are under the assumption that the

\footnotetext{
${ }^{7}$ Changing the Frisch elasticity can also be interpreted as assuming different ways that agent view the
} 
elasticity is double the one in the baseline calibration. GDP is about 0.8 percent lower than in the baseline by 2021, implying about 0.2 percentage points lower annual growth in the next 5 years. $^{8}$

We also perform a sensitivity test by changing the share of liquidity-constrained households $\psi$. The results in the short to medium run are quite robust to the change in that parameter and the intuition goes as follows. Since the amount of revenue used for individual accounts versus the solidarity pillar at the aggregate level remains constant (50 percent of 5 percentage points), decreasing the share of liquidity-constrained households, for instance, means that current pensions per capita will be higher but the total current transfers will stay the same. Similarly for future pensions to the OLG households. If we also consider that most of the decision rules are linear, in the aggregate results do not change.

\subsection{Alternative reform: using indirect taxes to finance solidarity pensions}

In this section, we analyze an alternative reform by assuming that the government finances the solidarity pillar with a consumption tax. Differentiating funding can be desirable because the reform tries to achieve two objectives of strengthening the individual pension accounts and supporting low-income old households through a solidarity pillar.

This alternative reform is revenue neutral relative to the authorities' reform analyzed in the previous section. This means that the consumption tax increase will be such that the additional revenue matches 50 percent of the revenue raised with the 5 percent increase in contributions in the previous reform case. The remaining 50 percent of the revenue will be raised by higher contributions (this is equivalent to assume that contributions will be raised by 2.5 percentage points).

Figure 4 shows the results when we simulate the reform using a consumption tax (red dashed line) instead of a labor tax as in authorities proposed reform (blue solid line) to provide the same funding to the solidarity pillar.

The impact of the reform on GDP is more muted relative to the reform proposed by authorities. GDP is only about 0.2 percent lower than the baseline by 2021 .

Raising part of the total funds of the reform using a less distortionary tax reduces the labor cost wedge so that labor supply and investment are less penalized. Funding via a consumption tax also implies less impairments of competitiveness so that exports decline less than in case of the authorities reform. Consumption of the liquidity-constrained is similar to the case of authorities reform proposal, since it is still supported by transfers (pensions).

In this case it's worth mentioning an important caveat to qualify the magnitude of the results. The alternative reform features the same or somewhat slightly higher consumption for the retirees (liquidity-constrained). This is because if, on the one hand, the consumption tax hurts retirees consumption, on the other hand, they are more than compensated by two

increased contributions as a labor tax or just forced savings, especially for the share of revenues used to increase individual savings accounts. When higher contributions are seeing partly as higher savings, agents change their consumption and labor plans by less. This effect is partially internalized by the OLG households, who see higher future pensions (transfers). For instance, dampening the elasticity of labor supply is equivalent to enhancing this effect for the part of proceeds that are used to increase individual accounts.

${ }^{8}$ Detailed results are available from the author upon request. 
Figure 4: Impact of an alternative reform: using indirect taxes to fund solidarity pensions
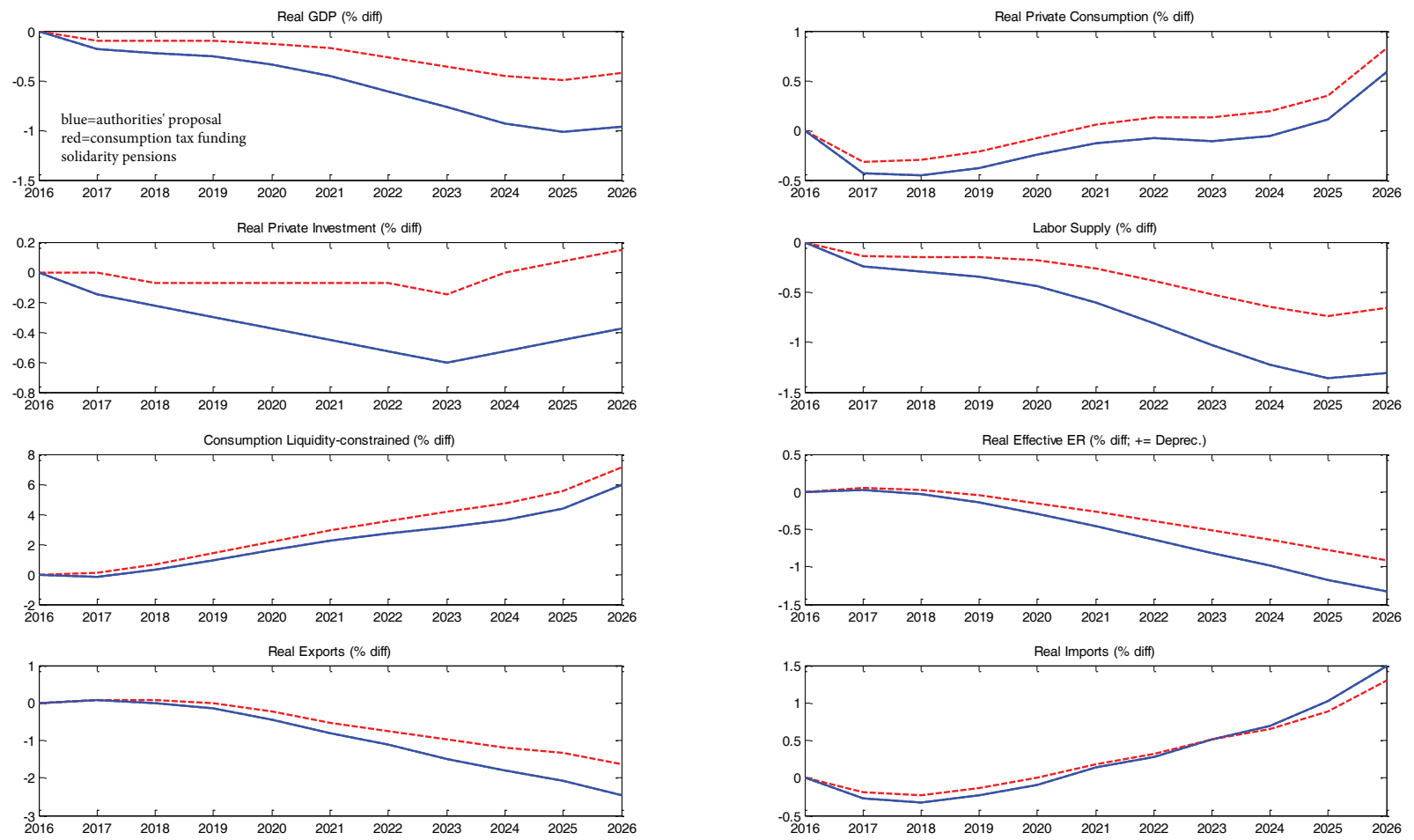

Source: IMF calculation. In percentage deviation from steady state.

additional sources of income: higher pensions (transfers) and labor income. In reality, retirees would not benefit from the channel of better labor incomes directly. ${ }^{9}$ The estimated impact on near-term growth are therefore biased upwards by this particular model feature.

\subsection{Alternative reform: higher contributions only to individual accounts}

In this section, we analyze the case that the revenue from higher contributions will be used only to finance pensions in the future, through the existing defined-contributions system. We assume the same increase as in the main authorities proposed reform: 5 percentage points. The additional revenue will be allocated to a public asset/fund (i.e. reduction of net debt for the government) and be used for rising transfers (mimicking higher individual savings accounts) in the future, starting gradually after 10 years.

Figure 5 shows the results when funds only go to individual accounts (red dashed line) as opposed to using a part to also finance the solidarity/PAYG pillar as in the mixed option

\footnotetext{
${ }^{9}$ As we already mentioned earlier, retirees (liquidity-constrained) do not decide on labor supply but labor income enters in their budget constraint as a passive transfer. The labor supply is decided by OLG agents. Since in this case part of the revenue is raised through a more efficient tax, labor supply is higher and labor income is higher, benefiting also the retirees. This effect in reality would only pass through secondary effects (better production costs and prices, higher transfers in the presence of higher tax collection with higher labor incomes etc.) and would be very muted.
} 
(blue solid line, as in Figure 3).

Figure 5: Impact of an alternative reform: higher contributions only to individual accounts
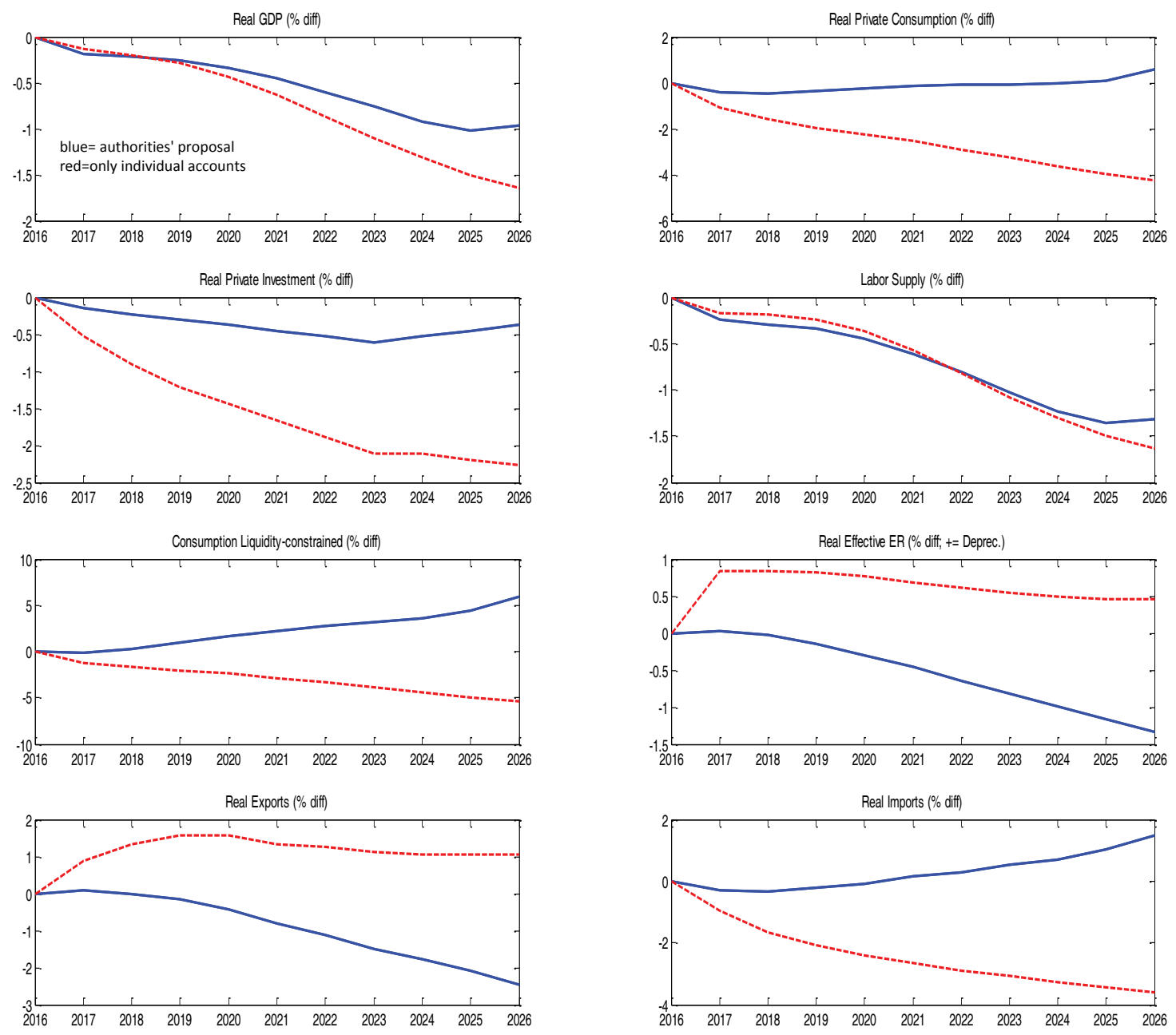

Source: IMF calculation. In percentage deviation from steady state.

In this case, aggregate consumption is lower over the near to medium run relative to case of the mixed option, given that now higher taxes and less labor income is not compensated by higher pensions for the current retirees. Aggregate savings are higher and nominal interest rates decrease by less relative to case of the mixed option, further discouraging domestic investment. ${ }^{10}$ Lower domestic inflation in the short run relative to the case of the authorities' proposal (because of lower domestic demand) leads to an improved REER position and stronger exports. Yet the fall in aggregate consumption and investment in the near term is stronger than in the case of the main authorities' proposal and GDP is about 0.7 percent lower than the baseline by 2021, equivalent to just below 0.2 percentage points lower growth in the next 5 to 6 years.

\footnotetext{
${ }^{10}$ The interest rate impact on investment is amplified by the presence of a financial accelerator a la Bernanke, Gertler and Gilchrist (1999) in the model.
} 


\section{Concluding remarks}

In this paper, we study the macroeconomic impact of a pension reform in Chile aimed at tackling low replacement rates and minimum pensions, using the IMF dynamic general equilibrium model (GIMF). The simulations are calibrated to replicate the authorities' reform proposal which raises mandatory contributions (employer side) and channels the additional proceeds, in a yet-to-be-determined share, to individual accounts and to the solidarity pension pillar.

We model increased contributions as a labor tax and find the impact of this reform on GDP to be negative in the near to the medium run. GDP is estimated to decline by 0.5 percent by 2021 relative to a baseline with no reform, as a result of labor tax distortions which lead to a fall in labor supply, investment, and a loss in competitiveness. We also estimate the impact of several variations of the main proposal. We find that the negative impact on GDP is moderately larger if, for example, revenues from increased contributions will be used only to improve future pensions, through individual savings accounts. Lower consumption, implied by lower current pensions (transfers) and higher savings in the near term generate lower goods demand and inflation and higher interest rates, relative to the main reform case. These in turn would depress domestic investment, despite creating a positive effect on the real effective exchange rate and net exports. In this case, GDP yearly growth would be almost 0.2 percentage point lower, or in GDP total 0.7 percent lower than baseline by 2021 .

Finally, because of the different reform objectives - to increase capital accumulation in individual pension accounts and to support low-income old households through a solidarity pillar - a differentiation in funding may be desirable. We analyze a third reform option package funded by a mix of higher contributions and indirect taxes. We find that this would carry lower growth costs than one funded exclusively by increased contribution rates.

Chile pensions system is based on solid fundamentals but for it to deliver pensions close to international standards any reform should take various trade offs into account In this paper, we estimate the tradeoffs between raising pensions now or pensions for future retirees. We show that the funding source matters for macroeconomic results in the near to the medium run and that an option that uses indirect taxation to support the solidarity pillar can entail lower costs. In addition, we only considered a basic announced increase in contributions.

Higher pensions can be achieved by other measures, considered by authorities but not announced yet, that could complement increased contributions requiring them to increase by less. Raising retirement age, especially for women, and extending mandatory contributions to the self-employed could help with both goals of increasing individual replacements rates and providing better minimum/solidarity pensions. 


\section{References}

[1] Auerbach Alan J. and Laurence J. Kotlikoff (1987), Dynamic Fiscal Policy, Cambridge University Press.

[2] Banco Central de Chile (2017), Evaluacin de impactos macroeconmicos de largo plazo de modificaciones al sistema de pensiones, Banco Central de Chile, Santiago, Chile.

[3] Bernanke Ben S., Mark Gertler and Simon Gilchrist (1999), The financial accelerator in a quantitative business cycle framework, In: Taylor John and M. Woodford (Eds.), Handbook of Macroeconomics, Elsevier.

[4] Bils Mark and Peter J. Klenow (2000), Does schooling cause growth?, American Economic Review, 90(5), pp. 1160-1183.

[5] Blanchard Olivier (1985), Debt, deficits, and finite horizons, Journal of Political Economy, 93(2), pp. 223-247.

[6] Chang Ly-June (1995), Business cycles with distorting taxes and disaggregated capital markets, Journal of Economic Dynamics and Control, vol. 19 (57), pp. 985-1009.

[7] Comisin Asesora Presidencial sobre el Sistema de Pensiones (Bravo Commission) (2015), Informe Final, Chile

[8] Corbo Vittorio (2014), Growth opportunities for Chile, Editorial Universitaria, Chile.

[9] De Gregorio Jose (2014), Notas sobre la reforma tributaria, Universidad de Chile, mimeo.

[10] De Nardi Mariacristina, Selahatin Imrohoroglu and Thomas J. Sargent (2001), Saving and Pension Reform in General Equilibrium Models, Oxford Papers on Economic Policy, vol. 17 (1), pp. 20-39.

[11] Fehr Hans, Sabine Jokisch and Laurence J. Kotlikoff (2005), Will China Eat Our Lunch or Take Us to Dinner? - Simulating the Transition Paths of the U.S., E.U., Japan, and China, Michigan Retirement Research Center Working Papers wp102, University of Michigan.

[12] Fehr Hans, Sabine Jokisch, Laurence J. Kotlikoff (2008), Dynamic Globalization and Its Potentially Alarming Prospects for Low-Wage Workers, NBER Working Papers 14527, Cambridge.

[13] Hassett Kevin and Glenn Hubbard (2002), Tax policy and business investment. In: Auerbach Alan, and Feldstein Martin (Eds.), Handbook of Public Economics, vol. 3., North-Holland, Amsterdam.

[14] Hsieh Chang-Tai, Erik Hurst, Chad Jones, and Peter Klenow (2015), The Allocation of talent and U.S economic growth, Econometrica, forthcoming. 
[15] Hsieh Chang-Tai and Miguel Urquiola (2006), The effect of generalized school choice on stratification and achievement: evidence from Chiles school voucher program, Journal of Public Economics, 90(8-9), pp. 1477-1503

[16] IMF (2015), October 2015 Fiscal Monitor, International Monetary Fund, Washington $\mathrm{DC}$

[17] Karam Philippe, Dirk Muir, Joana Pereira, and Anita Tuladhar (2010), Macroeconomic Effects of Public Pension Reforms, IMF Working Paper no. 10/297.

[18] Kumhof Michael, Douglas Laxton, Dirk Muir, and Susanna Mursula (2010), The Global Integrated Monetary and Fiscal Model (GIMF) Theoretical Structure, IMF Working Paper no. 10/34.

[19] Lusinyan Lusine and Dirk Muir (2013), Assessing the macroeconomic impact of structural reforms: The case of Italy, IMF Working Paper no. 13/22.

[20] Nishiyama Shinichi (2011), The Joint Labor Supply Decision of Married Couples and the Social Security Pension System, 2011 Meeting Papers 178, Society for Economic Dynamics.

[21] Nishiyama Shinichi and Kent Smetters (2007), Does Social Security Privatization Produce Efficiency Gains?, The Quarterly Journal of Economics, Oxford University Press, vol. 122(4), pages 1677-1719.

[22] OECD (2015), Education policy outlook 2015: Making reforms happen, OECD Publishing.

[23] Psacharopoulos George (2004), Returns to investment to education: A global update. World Development, 22, 13251343.

[24] Santoro Marika and Chao Wei (2011), Taxation, investment and asset pricing, Review of Economic Dynamics, 14(3), pp. 443-454.

[25] Tapia Waldo and Juan Yermo (2008), Fees in Individual Account Pension Systems: A Cross-Country Comparison, OECD Working Papers on Insurance and Private Pensions No. 27. 